\title{
Variations in Plant Zonation and Cover as Indicators of long-term changes in soil conditions: a case study in a mediterranean coastal salt marsh
}

\author{
José Álvarez-Rogel, María Nazaret González-Alcaraz \\ Departamento de Ciencia y Tecnología Agraria. Área de Edafología y Química Agrícola. \\ E.T.S. de Ingeniería Agronómica, Universidad Politécnica de Cartagena. \\ Paseo Alfonso XIII, 48, Cartagena, 30203 Murcia, Spain \\ jose.alvarez@upct.es; mnga@upct.es
}

\begin{abstract}
Summary. This study summarizes the changes (1991-2004) in plant distribution and cover in relation to soil factors in a salt marsh impacted by surplus of water from agricultural origin. An elevation of the groundwater level was observed, which led to a homogenization in the saline gradient. The changes were reflected in a shift in vegetation distribution which included the disappearance of most of the zonation observed in 1991.
\end{abstract}

Key words: plant zonation; soil-plant relationships; environmental gradients.

\section{Introduction}

Although the climate is considered a major driving variable affecting ecosystems, the effects of human impacts occur over much shorter time periods and thus can be easier identified. The latter is particularly true in wetlands due to in these ecosystems environmental gradients are usually pronounced, and this circumstance leads to the existence of a diversity of soils and plant communities in a short time and in a reduced area (Tiner 1999). When dramatic variations in the physical factors occur and are maintained in time, the distribution of the vegetation changes in response to the new conditions. Salt marshes are thus ideal to study the consequences of anthropogenic impacts on the evolution of the ecosystem.

The main goal of this study was to establish whether it is possible to detect trends of environmental changes in salt marshes based on observation of vegetation patterns.
For that, we studied the relationships between the changes in edaphic gradients and the species distribution and cover in a salt marsh that receives surplus water from agricultural activities.

\section{Study Area}

Twelve plots were located in the Marina del Carmolí salt marsh at SE Spain $\left(37^{\circ} 41^{\prime} \mathrm{N} ; 0^{\circ} 50^{\prime} \mathrm{W}\right)$, which is adjacent to the Mar Menor saline lagoon. The study zone is characterised by a semiarid Mediterranean climate, with a mean annual rainfall of $275 \mathrm{~mm}$, most of which falls in autumn and spring. The mean annual temperature is $17^{\circ} \mathrm{C}$ and the mean evapotranspiration rate is $856.8 \mathrm{~mm}$ per year. The surrounding areas of the Mar Menor have an intensive use and a surplus of agricultural water flows into the lagoon and into the coastal salt marshes (Lloret et al. 2005; Velasco et al. 2006; Álvarez-Rogel et al. 2006). 

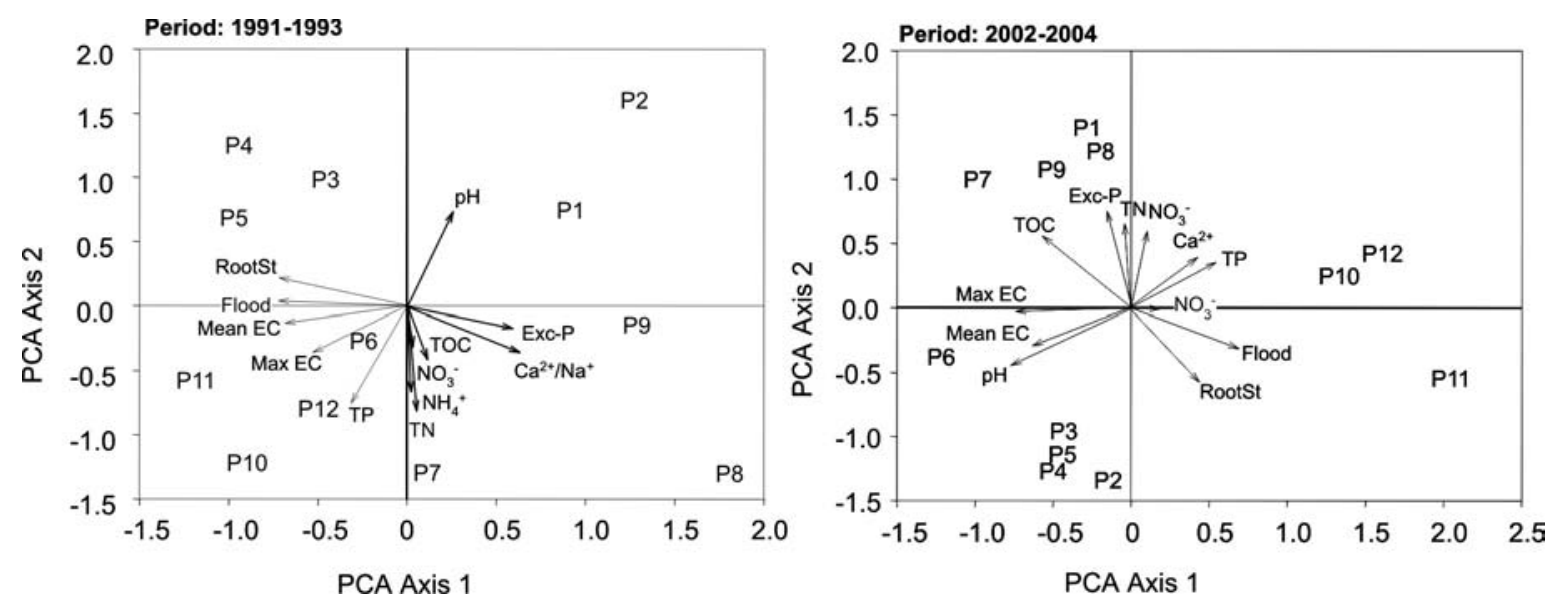

Figure 1. Results of the PCAs. Flood: average number of months with the water level $5 \mathrm{~cm}$ above the soil surface; RootSt: average number of months with the groundwater level less than $20 \mathrm{~cm}$ depth; EC: electrical conductivity; TP: total phosphorous; TN: total nitrogen; TOC: total organic carbon; Exc-P: exchangeable phosphorous. Modified from Álvarez-Rogel et al. (2007)

\section{Research Methods}

The plots were established in September 1991 and the floristic composition and cover of each species were determined in October 1991 and January 2004. Soil samples were regularly taken from each vegetation plot between October 1991 and September 1993 and between April 2002 and January 2004. The following analysis were performed: total organic carbon (TOC), total nitrogen (TN), pH, electrical conductivity (EC), soluble $\mathrm{Ca}^{2+}, \mathrm{Mg}^{2+}, \mathrm{Na}^{+}, \mathrm{K}^{+}, \mathrm{NH}_{4}^{+}$ and $\mathrm{NO}_{3}^{-}$, total phosphorous (TP) and exchangeable phosphorus (Exc-P). The groundwater level in the plots was determined at the sampling time by sinking a hole and allowing the interstitial water to refill it. Environmental gradients were examined separately for both sampling periods (1991-1993 and 2002-2004) with principal component analysis (PCA).

\section{Results and Discussion}

Patterns of spatial variation in soil salinity and flooding regime changed throughout the 13 -years plots studied, and they were accompanied by changes in vegetation distribution and species cover. We did not detect a clear pattern which indicated an increase in soil nutrient contents in the studied plots, except for sandy soils at the shoreline newly colonized by perennial vegetation in 2004 .

A general elevation of the water-table was observed between 1991-1993 and 2002-2004. This has led to a homogenization in the saline gradient. The topographically most depressed sites, which previously (1991-1993) had been more saline, were wetter in the 2002-2004 period leading to an increase in the dilution of the salts throughout all the year. In the topographically upper sites the water-table was shallower in the second period but they are not flooded, thus the capillary upward movement of saline water is more intense, and soil salinity remains higher than when the water-table was deeper. Gradient analysis reflected these changes.

The result of the PCA for the first sampling period showed a main gradient of flooding and EC on axis 1 and a secondary gradient of $\mathrm{pH}$ and nutrient content on axis 2 (Fig. 1). TOC and $\mathrm{NO}_{3}{ }^{-}$were the least important variables in the environmental gradient. In the second sampling period EC and flooding were also the variables defining the main environmental gradient (Fig. 1). However, in this case arrows reflecting the latter two variables pointed at opposite direction, hence reflecting that an increase in flooding periods led to a decrease in soil salinity. Plots that were depicted spread for the first sampling period were grouped for the second one, thus indicating an overlap in their soil conditions. These changes were reflected in a shift in vegetation distribution which included the disappearance of most of the zonation observed in 1991.

Possible factors influencing the depth of the groundwater level are the precipitation, the marine intrusion and a surplus of water from agricultural origin. Meteorological data did not reveal an increase in the rainfall regime in the zone between 1991 and 2004. On the other hand, the elevation of the groundwater level was not followed by a general increase in soil salinity, as would be expected if a marine intrusion of saline water had occurred. Hence, changes in the hydrological conditions in the salt marsh can be related to the surplus of agricultural water from areas of El Campo de Cartagena. Then, changes in vegetation distribution can be use as an indicator of environmental impacts in the salt marsh. 


\section{References}

Álvarez-Rogel J., Jiménez-Cárceles F. J. \& EgeaNicolás C., 2006, Phosphorus and nitrogen content in the water of a coastal wetland in the Mar Menor lagoon (SE Spain): relationships with effluents from urban and agricultural areas. Water Air and Soil Pollution 173: 21-38.

Álvarez-Rogel J., Jiménez-Cárceles F. J., Roca M. J. \& Ortiz R., 2007, Changes in soils and vegetation in a Mediterranean coastal salt marsh impacted by human activities, Estuarine Coastal and Shelf Science 73: $510-526$.
Lloret J., Marín A., Marín-Guirao L. \& Velasco J., 2005, Changes in macrophytes distribution in a hypersaline coastal lagoon associated with the development of intensively irrigated agriculture, Ocean \& Coastal Management 48: 828-842.

Tiner R. W., 1999, Wetlands Indiators. A guide to wetland identification, delineation, classification, and mapping. Lewis Publishers, CRC Press. Boca Raton, USA.

Velasco J., Lloret L., Millán A., Barahona J., Abellán P., Sánchez-Fernández D., 2006, Nutrient and particulate inputs into the Mar Menor lagoon (SE SPAIN) from an intensive agricultural watershed, Water Air and Soil Pollution 176: 37-56. 